06

\title{
Гидрофобные свойства пленки фторполимера, покрывающей наночастицы золота
}

\author{
() А.И. Сафоонов ${ }^{1}$, С.В. Старинский ${ }^{1}$, В.С. Суляева ${ }^{2}$, \\ Н.И. Тимошенко ${ }^{1}$, Е.Я. Гатапова ${ }^{1}$ \\ ${ }^{1}$ Институт теплофизики им. С.С. Кутателадзе СО РАН, Новосибирск \\ ${ }^{2}$ Институт неорганической химии им. А.В. Николаева СО РАН, \\ Новосибирск \\ E-mail: vika@itp.nsc.ru
}

Поступило в Редакцию 12 апреля 2016 г.

Методом активации на горячей поверхности (Hot Wire Chemical Vapor Deposition) осаждены тонкие фторполимерные пленки на наночастицы золота различного размера. С помощью многофункционального модульного прибора DSA-100 KRUSS определены значения краевых углов смачивания поверхности водой и $\mathrm{CH}_{2} \mathrm{I}_{2}$, также определена свободная энергия поверхности покрытий. Установлено влияние инкапсулированных частиц золота на гидрофобные свойства полученных покрытий.

DOI: 10.21883/PJTF.2017.03.44226.16293

В настоящее время активно ведутся работы в области создания супергидрофобных материалов и покрытий различного назначения. В работах [1-3] авторы разрабатывают методы нанесения гидрофобных покрытий для использования в различных областях практических применений и на различные материалы.

Гидрофобность определяется характеристиками материала (свободной энергией поверхности) и структурой приповерхностного слоя, микро- и наномасштабной шероховатостью. Например, у фторполимеров низкая энергия поверхности, и поэтому краевой угол смачивания водой такой поверхности составляет более $100^{\circ}$ [4]. Влияние неоднородностей и шероховатости поверхности может происходить при частичной смачиваемости поверхности (режим Касси-Бакстера) или при полной смачиваемости (режим Венцеля) [5]. Как правило, уменьшение поверхностной энергии и нано- и микромасштабная шеро- 
Таблица 1. Параметры образцов с частицами золота

\begin{tabular}{c|c|c}
\hline № образца & $\begin{array}{c}\text { Толщина пленки до отжига, } \\
\mathrm{nm}\end{array}$ & $\begin{array}{c}\text { Средний размер } \mathrm{Au} \mathrm{HЧ,} \\
\mathrm{nm}\end{array}$ \\
\hline 1 & 2 & 12 \\
2 & 4 & 22 \\
3 & 10 & 55
\end{tabular}

ховатость поверхности позволяют достигнуть бо́льших значений углов смачивания. Например, в работах [6,7] получены фторполимерные покрытия с различной морфологией в зависимости от условий осаждения. Показано [6], что в зависимости от режима осаждения пленки угол смачивания изменяется от $120^{\circ}$ до $170^{\circ}$.

В настоящей работе обнаружено влияние наличия наночастиц $(\mathrm{HЧ})$ золота под фторполимерной пленкой на ее смачиваемость водой. Наночастицы золота размером от 10 до $60 \mathrm{~nm}$ синтезировались на полированном кремнии. Затем на эту поверхность с наночастицами золота осаждалась пленка фторполимера толщиной порядка $20 \mathrm{~nm}$. Оказалось, что угол смачивания таких композитов меняется от $100^{\circ}$ до $130^{\circ}$ и зависит от наличия частиц золота, которые „спрятаны“ под фторполимерной пленкой.

Для получения образцов с наночастицами золота были осаждены тонкие пленки золота толщиной от 2 до $10 \mathrm{~nm}$ на поверхность кремния (111) $5 \times 20 \mathrm{~mm}$ методом ионного распыления на установке JEOL Auto Fine Coater - JFC-1600. Параметры процесса представлены в табл. 1. Полученные пленки были отожжены в вакуумной камере при температуре $550^{\circ} \mathrm{C}$ и давлении $10^{-1} \mathrm{~Pa}$ в течение $15 \mathrm{~min}$. При отжиге на поверхности подложки из пленки формируются наночастицы, размер которых зависит, в частности, от толщины исходной пленки и температуры отжига.

На полученные образцы с наночастицами золота были осаждены фторполимерные покрытия методом Hot Wire Chemical Vapor Deposition (HWCVD) [8,9]. Экспериментальная установка описана в работе [6]. Гладкие бездефектные пленки фторполимера были получены при следующих условиях: расход газа-предшественника $\mathrm{C}_{3} \mathrm{~F}_{6} \mathrm{O}$ составлял $20 \mathrm{sccm}$; температура активирующей сетки около $680^{\circ} \mathrm{C}$; давление газа-предшественника $50 \mathrm{~Pa}$; расстояние активатор-подложка $50 \mathrm{~mm}$; время осаждения $7 \mathrm{~min}$; температура подложки - около $30^{\circ} \mathrm{C}$.

Письма в ЖТФ, 2017, том 43, вып. 3 


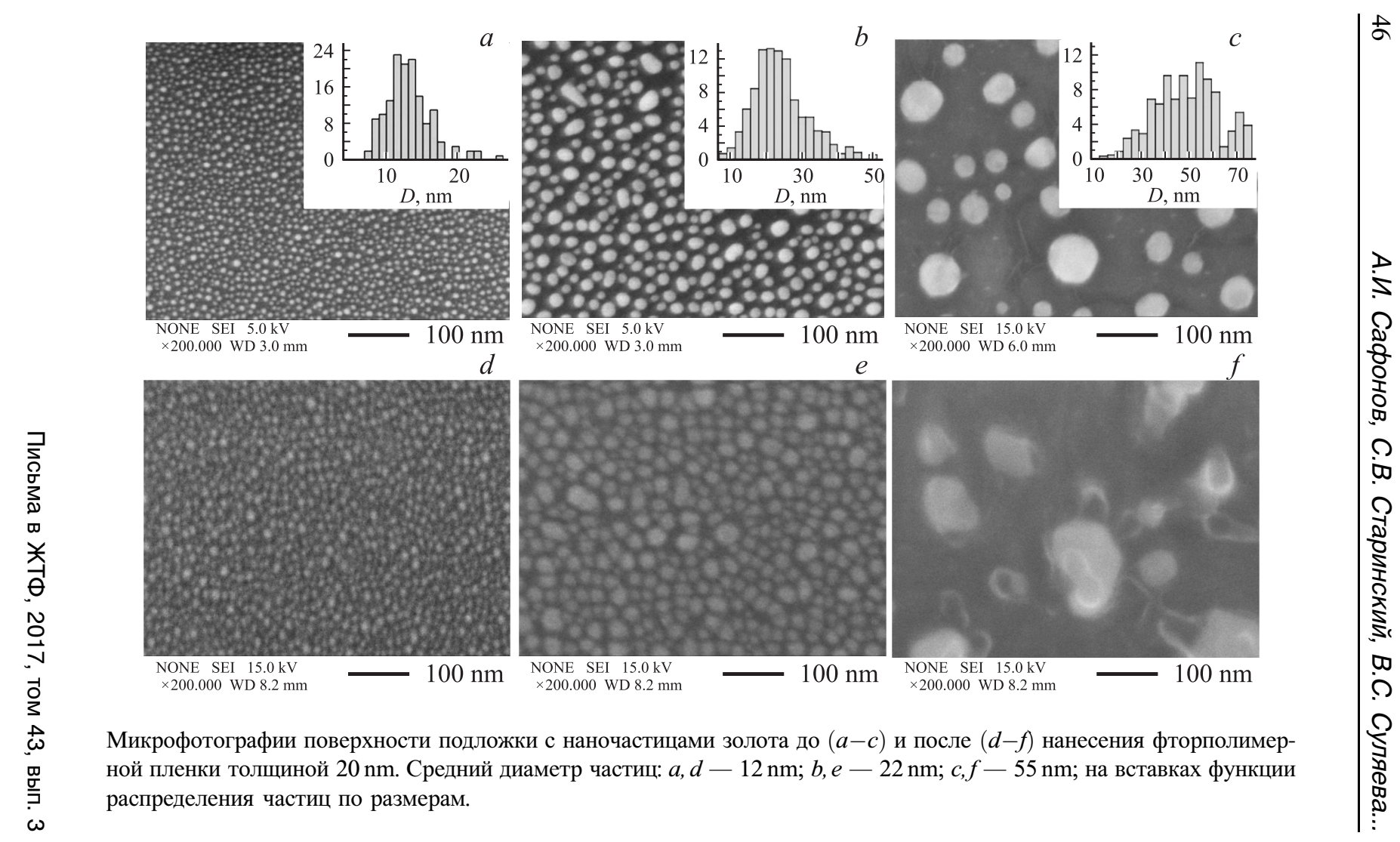


Таблица 2. Значения $y$ и расчетные величины $\alpha_{c}$ по формуле Венцеля

\begin{tabular}{c|c|c|c}
\hline Параметр & Образец 1 & Образец 2 & Образец 3 \\
\hline$y$ & 1.00076 & 1.0028 & 1.127 \\
$\alpha_{c}$ & $166.1^{\circ}$ & $166.5^{\circ}$ & -
\end{tabular}

На рисунке представлены снимки со сканирующего электронного микроскопа JEOL JSM-6700F наночастиц золота $(a-c)$ и композитных покрытий $(d-f)$, полученных в эксперименте. С помощью режима BSE (backscattered electrons) микроскопа установлено, что форма и размер золотых наночастиц не изменяются при осаждении фторполимерного покрытия. Таким образом, могут быть получены металлополимерные композиты с контролируемой геометрией.

Для определения степени шероховатости были проведены измерения профилей поверхности образцов на атомном силовом микроскопе Solver P47H (NT MDT, Zelenograd). По результатам измерений определена величина отношения длины линии профиля поверхности к длине ее проекции (табл. 2). Средняя амплитуда шероховатости составила $1.4 \mathrm{~nm}$ для образца $1,3 \mathrm{~nm}$ для образца 2 и $50 \mathrm{~nm}$ для образца 3.

Для анализа влияния геометрических характеристик полученных поверхностей на краевой угол смачивания были проделаны оценки по формуле Венцеля [5]

$$
\cos \left(\alpha_{c}\right)=y \cos (\alpha),
$$

где $\alpha_{c}-$ угол смачиваемости шероховатой поверхности, $\alpha-$ угол смачиваемости гладкой поверхности, $y$ - отношение длины контура линии к ее проекции на плоскость поверхности. Угол $\alpha=166^{\circ}$, который соответствует нашим измерениям по смачиваемости водой фторполимерного покрытия на полированном кремнии [6] (образец 4 в табл. 3). Значения угла $\alpha_{c}$ для исследуемых образцов представлено в табл. 2.

Из результатов расчета следует, что для образцов 1 и 2 шероховатость практически не меняет угол смачиваемости, а для образца 3 $\left|\cos \alpha_{c}\right|>1$, что свидетельствует о неприменимости данной формулы в этом случае вследствие неполного смачивания поверхности.

С помощью многофункционального модульного прибора DSA-100 KRUSS проведено измерение углов смачивания и свободной энергии поверхности образцов $F$ (табл. 3). Измерения проведены для двух

Письма в ЖТФ, 2017, том 43, вып. 3 
Таблица 3. Результаты измерений углов смачивания полярной $\left(\mathrm{H}_{2} \mathrm{O}\right)$ и неполярной $\left(\mathrm{CH}_{2} \mathrm{I}_{2}\right)$ жидкостью и энергия поверхности

\begin{tabular}{c|c|c|c}
\hline Образец & $\begin{array}{c}\text { Угол смачивания } \\
\mathrm{H}_{2} \mathrm{O}, \mathrm{deg}\end{array}$ & $\begin{array}{c}\text { Угол смачивания } \\
\mathrm{CH}_{2} \mathrm{I}_{2}, \mathrm{deg}\end{array}$ & $\begin{array}{c}\text { Свободная энергия } \\
\text { поверхности } F, \mathrm{mN} / \mathrm{m}\end{array}$ \\
\hline 1 & 105 & 77 & 25.5 \\
2 & 101 & 73 & 27.3 \\
3 & 134 & 79 & 20.4 \\
4 & 166 & 118 & 4.7
\end{tabular}

жидкостей - вода (полярная жидкость) и дийодметан $\mathrm{CH}_{2} \mathrm{I}_{2}$ (неполярная). По данным [4] для поверхности тефлона (нетонкой пленки фторполимера) угол смачиваемости водой $\sim 105^{\circ}$ и дийодметаном $\left(\mathrm{CH}_{2} \mathrm{I}_{2}\right) 85^{\circ}$. По всей видимости, расхождение связано с размерными эффектами, проявляющимися в пленке фторполимера с наномасштабной структурой поверхности.

Измеренные углы смачивания водой для полученных образцов (табл. 3) отличаются от расчетных значений табл. 2. Результаты расчетов свидетельствуют о слабом влиянии шероховатости поверхности на угол смачивания вследствие малости значения $y$. Следовательно, для данных образцов значение угла смачивания определяется в основном свободной энергией поверхности $F$. По результатам измерений установлено, что включение золотых наночастиц во фторполимерную пленку приводит к заметному изменению $F$. Таким образом, наличие в пленке фторполимера наночастиц золота приводит к изменению свободной энергии поверхности фторполимера и соответственно к изменению угла смачивания.

Процедура определения свободной энергии была реализована с помощью метода Оунса, Вендта, Рабеля и Кьельбле, где предполагается, что энергия поверхности твердого тела включает две составляющие: дисперсионную и полярную [10]. Дисперсионная составляющая включает силы Ван-дер-Ваальса и другие неспецифические взаимодействия, полярная составляющая - сильные взаимодействия и водородные связи. Силы Ван-дер-Ваальса могут действовать на глубину порядка $100 \mathrm{~nm}$ [11]. Ясно, что при толщине фторполимерной пленки $20 \mathrm{~nm}$ жидкость может „чувствовать“ присутствие инкапсулированных наночастиц золота. Металл, как правило, обладает большей поверхностной 
энергией, чем фторполимер; следовательно, присутствие наночастиц золота будет увеличивать поверхностную энергию.

Таким образом, получены композитные покрытия, состоящие из наночастиц золота и осажденной сверху тонкой пленки фторполимера. Обнаружено, что наличие инкапсулированных наночастиц золота влияет на гидрофобные свойства тонкой фторполимерной пленки. Показана прямая зависимость изменения гидрофобных свойств поверхности образцов от наличия и размера инкапсулированных наночастиц золота.

Авторы благодарят Е.О. Кириченко за помощь при проведении измерений на приборе DSA-100 KRUSS.

Работа выполнена при частичной финансовой поддержке в рамках гранта РФФИ (№ 15-38-20411А), гранта Президента РФ (МК5052.2016.8, получение образцов), гранта Российского научного фонда (соглашение № 14-19-01755, исследование свойств поверхности) и при поддержке Министерства образования и науки РФ на оборудовании ЦКП „Наноструктуры“ (исследование строения поверхности полученных образцов).

\section{Список литературы}

[1] Бойнович Л.Б., Емельяненко А.М. // Успехи химии. 2008. V. 77 (7). С. 619 638.

[2] Lau K.K.S., Bico J., Teo K.B.K. et al. // Nano Lett. 2003. V. 3. N 12. P. 17011705.

[3] Придатко А.В., Миронюк А.В., Свидерский В.А. // Восточно-Европейский журнал передовых технологий. 2015. Т. 5. № 5 (77). С. 30-41.

[4] Адамсон А. Физическая химия поверхностей. М.: Мир, 1979.

[5] Дмитриев А.С. Введение в нанотеплофизику. М.: БИНОМ, 2015.

[6] Safonov A., Sulyaeva V., Timoshenko $N$. et al. // MATEC Web of Conferences. 2015. V. 37. P. 01047. DOI: $10.1051 /$ matecconf $/ 20153701047$ http://dx.doi.org/10.1051/matecconf/20153701047.

[7] Ребров А.К., Сафонов А.И., Тимошенко Н.И. // Письма в ЖТФ. 2009. Т. 35. B. 9. C. 11-16.

[8] Lau K.S., Mao Yu., Lewis H.G.P. et al. // Thin Solid Films. 2006. V. 501. P. 211215.

[9] Takachi M., Yasuoka H., Ohdaira K. et al. // Thin Solid Films. 2009. V. 517. P. 3622-3624.

[10] De Gennes P.G. // Rev. Mod. Phys. 1985. V. 57. P. 827-863.

[11] Дерягин Б.В., Чураев Н.В., Муллер В.М. Поверхностные силы. М.: Наука, 1985.

4 Письма в ЖТФ, 2017, том 43, вып. 3 